Western University

Scholarship@Western

Management and Organizational Studies

Management and Organizational Studies

Publications

Department

$10-14-2020$

\title{
Making the World a Better Place: How Crowdfunding Increases Consumer Demand for Social-Good Products
}

\author{
Bonnie Simpson \\ Western University, bonnie.simpson@uwo.ca \\ Martin Schreier \\ Webster University, Vienna, martin.schreier@wu.ac.at \\ Sally Bitterl \\ Webster University, Vienna, sally.bitterl@wu.ac.at \\ Katherine White \\ University of British Columbia, katherine.white@sauder.ubc.ca
}

Follow this and additional works at: https://ir.lib.uwo.ca/mospub

Part of the Business Administration, Management, and Operations Commons, and the Work, Economy and Organizations Commons

\section{Citation of this paper:}

Simpson B, Schreier M, Bitterl S, White K. EXPRESS: Making the World a Better Place: How Crowdfunding Increases Consumer Demand for Social-Good Products. Journal of Marketing Research. October 2020. doi:10.1177/0022243720970445 


\title{
Making the World a Better Place:
}

\section{How Crowdfunding Increases Consumer Demand for Social-Good Products}

\author{
forthcoming (2020) in Journal of Marketing Research
}

\author{
Bonnie Simpson \\ Associate Professor, DAN Department of Management and Organizational Studies \\ Western University, London, Ontario, Canada, N6A 5C2 \\ $+1-519-661.2111$ x. 84927 \\ bonnie.simpson@uwo.ca \\ Martin Schreier \\ Professor of Marketing, Institute of Marketing Management \\ WU Vienna, 1020 Vienna, Austria \\ +43-1-31336-4609 \\ martin.schreier@wu.ac.at \\ Sally Bitterl \\ Teaching and Research Associate, Institute of Marketing Management \\ WU Vienna, 1020 Vienna, Austria \\ $+43-1-31336-4625$ \\ sally.bitterl@wu.ac.at \\ Katherine White \\ Professor of Marketing and Behavioural Science, Sauder School of Business \\ University of British Columbia, Vancouver, BC, Canada, V6T 1Z2 \\ $+1-604-827-3711$ \\ katherine.white@sauder.ubc.ca
}

Acknowledgements: The authors would like to thank the Social Sciences of Humanities Research Council of Canada Explore Grant program for their financial support of this project; Ilaria Salatino, Julie Hommik, Justine Vincent, and Brittany Wagner for research assistance; and, the review team for their feedback and support. 


\begin{abstract}
Crowdfunding has emerged as an alternative means of financing new ventures wherein a large number of individuals collectively back a project. This research specifically looks at rewardbased crowdfunding, where those who take part in the crowdfunding process receive the new product for which funding is sought in return for their financial support. This work illustrates that consumers make fundamentally different decisions when considering contributing their money to crowdfund versus purchase a product. Six studies demonstrate that compared to a traditional purchase, crowdfunding more strongly activates an interdependent mindset and, as a result, increases consumer demand for social-good products (i.e., products with positive social and/or environmental impact). The research further highlights that an active involvement in the crowdfunding process is necessary to increase demand for social-good products: When a previously crowdfunded product is already to market, the effect is eliminated. Finally, it is demonstrated that crowdfunding participants exhibit an increased demand for social-good products only when collective efficacy (i.e., one's belief in the collective's ability to bring about change) is high.
\end{abstract}

Keywords: crowdfunding, social-good products, interdependent self-construal, construal level, collective-efficacy beliefs. 
Crowdfunding has emerged as a popular complement to funding new ventures and product launches via standard financial intermediaries. Crowdfunding involves financing new products and services by relying on a large number of individuals who collectively back a given venture. On platforms such as Kickstarter and Indiegogo, for example, hundreds of thousands of start-ups have successfully pitched and sold their new products to millions of people (Agrawal, Catalini, and Goldfarb 2015; Kuppuswamy and Bayus 2017; Mollick 2014). Indeed, data from the Pew Research Center's American Trends Panel (2015) indicate that 25\% of Americans have contributed to a project on a crowdfunding platform and $47 \%$ of Americans are aware of crowdfunding. While crowdfunding has been labeled as revolutionary from a start-up financing perspective (Gubler 2013; Mollick 2014), and some studies have considered characteristics that lead consumers to become project backers (Ryu and Kim 2016; Zhang and Chen 2018; Zvilichovsky, Danziger, and Steinhart 2018), research has yet to explore how participating in crowdfunding might impact the consumer decision-making process. We argue that this is a critical gap in the literature, particularly given that organizations have begun to use crowdfunding not only as a source of financing but also as a marketing platform to ensure a ready market for their offerings (Brown, Boon, and Pitt 2017).

In the current research, we focus on reward-based crowdfunding, wherein individuals who back a venture receive the focal product in return for their financial support if enough funds are raised and the project comes to fruition (Mollick 2014). A relevant comparison to this form of crowdfunding is a traditional purchase transaction (Bitterl and Schreier 2018; Blaseg, Schulze, and Skiera 2020). Although there are differences between these transaction types which we will discuss further below, in both cases the consumer is asked to allocate a certain amount of money and receives a product in return. We make the novel prediction that consumers asked to engage 
in seemingly similar behaviors (i.e., paying money in exchange for eventually receiving a given product) will exhibit unique attitudes and choices as a function of whether the transaction is via crowdfunding or a more conventional purchase. In particular, we propose and find that a crowdfunding as opposed to a classic purchase transaction increases consumer demand for social-good products (i.e., products with positive social and/or environmental impact). Further, we suggest that this effect emerges because crowdfunding activates a more interdependent selfconstrual (i.e., it heightens one's sense of the self as interconnected with others; Markus and Kitayama 1991), which leads consumers to more strongly desire products that highlight socialgood aspects.

This research makes a number of contributions to the literatures on crowdfunding, prosocial choice, and self-construal. Most critically, we offer a first systematic analysis of differences in the consumer decision-making process between crowdfunding and more traditional purchase transactions. In particular, we propose and find that when money is exchanged for a product in a crowdfunding transaction as opposed to a purchase transaction, consumer demand for social-good products increases. That is, we propose that the type of transaction (crowdfunding vs. purchase) can lead consumers to prefer qualitatively different types of products. This makes a contribution to existing work in the crowdfunding domain that largely examines behaviors within crowdfunding (e.g., Dai and Zhang 2019; Kuppuswamy and Bayus 2017; Zvilichovsky, Danziger, and Steinhart 2018). Critically, the current findings cannot be attributed to self-selection such that certain segments of consumers are more strongly drawn to crowdfunding platforms. Instead, our evidence is based on a series of experiments with random assignment to crowdfunding versus purchase transactions. In sum, this is the first 
research to examine whether crowdfunding — compared to a more traditional purchase — can produce differential consumer demand for certain types of products.

More broadly, these findings extend related research on the consequences of different types of transactions. For example, Zlatev and Miller (2016) show that consumers react more positively to the offer of buying an item with the proceeds going to charity (known as causerelated marketing) versus making a donation and receiving the same item as a gift in return. Relatedly, Gneezy et al. (2010) show that cause-related marketing campaigns are more profitable under a pay-what-you-want regime (the consumer decides how much to pay) compared to a traditional fixed-price regime (the firm determines the price; see also Jung et al. 2017). Our findings add to this body of research by suggesting that a given type of transaction (i.e., crowdfunding vs. purchase) may also more fundamentally shape consumer demand for socialgood products.

Third, we highlight a novel mechanism underlying our effect—namely, that crowdfunding (vs. purchasing) more strongly activates an interdependent self-construal, which increases consumer demand for social-good products. This is a direct contribution to the selfconstrual literature. While consumer research has developed a broad understanding of the consequences of self-construal, there has been little focus on situational antecedents of selfconstrual beyond using language and narrative priming tasks (e.g., Duclos and Barasch 2014; Hong and Chang 2015; Lalwani and Shavitt 2013; Simpson, White, and Laran 2018; White and Simpson 2013; Winterich and Barone 2011). This current work highlights the role of natural market transactions in making a particular self-construal salient. This is a novel insight and potential catalyst for future self-construal research, suggesting that there might be other real-life circumstances that shift consumers' self-views. 
Fourth, we identify two additional factors specific to crowdfunding that offer further insight. Involvement in the actual process of crowdfunding is necessary to realize the increased demand for social-good products: When a previously crowdfunded product is already available to the market, the effect is eliminated. Additionally, crowdfunding participants demonstrate an increased demand for social-good products only when collective efficacy (i.e., one's belief in the collective's ability to bring about change; Bandura 1997) is high. In highlighting the role of collective efficacy, we present this construct as a promising variable to consider in the field of marketing. While collective efficacy has received attention in domains such as organizational leadership (Chen and Bliese 2002) and political action (Velasquez and LaRose 2015), it has not

yet been widely explored in consumer research. We hope our findings will have practical value for ventures that are considering a product launch on a crowdfunding platform.

\section{THEORETICAL DEVELOPMENT}

\section{Crowdfunding versus Purchase Transactions}

At first glance, one might argue that reward-based crowdfunding does not substantially differ from the classic purchasing process. In essence, both paradigms involve the exchange of a certain amount of money and both lead to the consumer eventually receiving the focal product in return. Indeed, the crowdfunding literature often equates reward-based crowdfunding with more conventional preselling (Belleflamme, Lambert, and Schwienbacher 2014; Brown, Boon, and Pitt 2017; Mollick 2014). For example, Indiegogo describes its project backers as "early adopters searching for interesting gadgets and innovative items," and crowdfunding participants frequently describe their engagement as "just another way to shop online" (Gallaga 2013). Thus, 
one reasonable prediction is that the individual consumer will respond similarly to an exchange offered as a crowdfunding opportunity and one offered as a purchase, evaluating the attributes and benefits of the product option(s) and, according to their preferences, making a decision. This point of view implies that the type of transaction (crowdfunding vs. purchase) should not differentially impact the consumer decision-making process.

On the other hand, while there are many similarities between traditional purchasing and reward-based crowdfunding, there are also meaningful elements of difference to consider. For instance, in crowdfunding as opposed to purchase transactions, there may be a delay in receiving the product, as it may not be manufactured yet (Brown, Boon, and Pitt 2017). Because of this, crowdfunding carries an element of risk related to whether the project will be realized at all (Brown, Boon, and Pitt 2017). Literature has also demonstrated that crowdfunding consumers are motivated to get products made. For instance, crowdfunding participants are more inclined to support a given project if they feel they are pivotal in safeguarding future product availability (Kuppuswamy and Bayus 2017; Zvilichovsky, Danziger, and Steinhart 2018) and are particularly likely to support a project when it approaches its target goal (Dai and Zhang 2019).

\section{The Collective Nature of Crowdfunding and Interdependent Self-construal}

While the above effects have been demonstrated within the crowdfunding literature, we focus on another key potential difference between reward-based crowdfunding and purchase transactions that we suggest leads to distinct choices. We make the argument that, by its very nature, crowdfunding is an inherently collective endeavor (Mollick 2018). Because of this, crowdfunding may activate an interdependent self-construal, which is characterized by viewing the self as interconnected with others (Markus and Kitayama 1991; Singelis 1994). A heightened sense of interdependence may then lead to heightened demand for social-good products. 
There is extensive evidence that the degree to which a person views the self as interdependent (i.e., the self is connected with others) or independent (i.e., the self is seen as unique and separate from others) can impact consumer attitudes and choices (Duclos and Barasch 2014; Lalwani and Shavitt 2013; Simpson, White, and Laran 2018; Winterich and Barone 2011). For instance, those with an interdependent (vs. independent) self-construal activated have been shown to be more risk-seeking in financial (vs. social) choices (Mandel 2003), more risk-averse as a function of the activation of prevention-focused goals (Hamilton and Biehal 2005), more persuaded by prevention- (vs. promotion)-focused information (Aaker and Lee 2001), and more prone to using price information to judge quality (Lalwani and Shavitt 2013). Importantly, those who are more interdependent are more socially focused (Obhi, Hogeveen, and Pascual-Leone 2011) and more likely to engage in actions that help the collective as opposed to their own individual interests (Winterich and Barone 2011).

While these two distinct ways of viewing oneself (independent vs. interdependent) are often conceptualized in terms of measured individual differences (e.g., Markus and Kitayama 1991; Singelis 1994), there is evidence that contextual factors can temporarily activate a heightened salience of one over the other (Shavitt, Lee, and Johnson 2008; White, Argo, and Sengupta 2012). For instance, a specific self-construal can be activated by having participants read a short story or watch video clips (Mandel 2003), focusing attention on individual or collective pronouns (Agrawal and Maheswaran 2005; Brewer and Gardner 1996), or by developing within-appeal information with emphasis on collective or independent language (Aaker and Lee 2001; White and Simpson 2013).

While the above examples draw largely from priming tasks that are rooted in the type of language used, we critically generalize our understanding of self-construal priming by suggesting 
that natural marketplace circumstances may also activate a more interdependent (vs. independent) self-construal. In particular, we predict that crowdfunding activates thoughts of an interdependent collective, consistent with what would be expected of a salient interdependent self-construal (Markus and Kitayama 1991). While research has not explicitly demonstrated this consequence of crowdfunding, existing literature is suggestive in this regard. For instance, qualitative interviews with crowdfunding participants have uncovered feelings of collaboration and connectedness to a community as a result of engaging in crowdfunding, which is consistent with the activation of an interdependent mindset (Gerber and Hui 2016). Additionally, Galak, Small, and Stephen (2011) find that lenders favor individual borrowers who are socially similar to themselves (e.g., gender, occupation, first-name initial), and Burtch, Ghose, and Wattal (2013) report that lenders prefer culturally similar and geographically proximate borrowers. These findings are consistent with the activation of a relatively interdependent self-construal and support of one's ingroup. Drawing on this work, we propose that a crowdfunding (vs. purchase) transaction will more strongly activate an interdependent (vs. independent) self-construal. Interdependent Self-construal and Demand for Social-good Products

We further suggest that the interdependent self-construal that becomes activated in a crowdfunding versus purchase transaction increases consumer demand for products with positive social and/or environmental impact (i.e., social-good products). We suggest that this occurs because an interdependent self-construal results in a heightened focus on collective goals (Downie et al. 2006; Markus and Kitayama 1991) and leads to increases in actions that support the social good (Arnocky, Stroink, and DeCicco 2007; Burton, Gore, and Sturgeon 2012; Chuang, Xie, and Liu 2016; Moorman and Blakely 1995; Winterich and Barone 2011). Our theorizing is consistent with literature demonstrating that an interdependent (vs. independent) 
self-construal leads to greater cooperation (Utz 2004), engagement in corporate social responsibility initiatives (Simpson, Robertson, and White 2019), and willingness to support prosocial causes (Vaidyanathan, Aggarwal, and Kozlowski 2013). Moreover, research on lending-based crowdfunding on Kiva suggests that lenders are influenced by prosocial elements such as narratives framed as an opportunity to help others (Allison et al. 2015; Dai and Zhang 2019). More specific to reward-based crowdfunding, Kickstarter projects with a sustainability orientation (Calic and Mosakowski 2016) or use of prosocial words (Pietraszkiewicz, Soppe, and Formanowicz 2017) demonstrate a higher funding likelihood. Although this collective evidence is suggestive, we do not yet know whether the transaction type (crowdfunding vs. purchase) causally affects self-construal, and through this, influences product demand; or alternatively, whether differently minded people engage in crowdfunding. Our conceptualization predicts that an experimental manipulation of transaction (i.e., crowdfunding vs. purchase) will increase consumer demand for social-good products. More formally, we hypothesize:

$\mathrm{H}_{1}$ : Consumers in a crowdfunding versus purchase transaction will demonstrate a stronger demand for social-good products.

Furthermore, based on our discussion in the preceding section, we predict that this effect will be statistically mediated by interdependent self-construal.

$\mathrm{H}_{2}$ : The relationship predicted in $\mathrm{H}_{1}$ will be mediated by self-construal such that a crowdfunding (vs. purchase) transaction will activate a more interdependent selfconstrual, which will predict consumer demand for social-good products.

\section{Actual Crowdfunding Involvement as a Necessary Condition}

We further test two additional factors regarding crowdfunding specifically to highlight when the postulated effects can be expected to occur. The first draws on our proposition that 
involvement in the crowdfunding process activates a relatively more interdependent selfconstrual. To strengthen support for this notion, we explore whether it is necessary that a consumer be actively involved in the process of crowdfunding, or alternatively, whether simply learning that a product has been previously developed via crowdfunding is sufficient to increase consumer demand for social-good products. We expect that when the opportunity to be involved in crowdfunding the product is removed (because the crowdfunding process is over and the product has been successfully developed for purchase), heightened demand for social-good products will be attenuated. This is because the focal transaction switches back to regular purchase and, as a result, the consumer's mindset should mimic the classic purchase mindset. In particular, we argue that compared to a crowdfunding transaction, an interdependent selfconstrual should not be activated as strongly when a product for purchase has been previously financed via crowdfunding, due to elimination of the collective element of contributing. As a result, under conditions where a previously crowdfunded product is already available for purchase, the postulated effects should be mitigated. We hence predict:

$\mathrm{H}_{3}$ : There is an attenuation of the effect of transaction (crowdfunding vs. purchase) on consumer demand for social-good products when the crowdfunded product is already available for purchase.

\section{The Role of Collective Efficacy}

Given that those with a more interdependent self-construal (i.e., those in a crowdfunding transaction) have a heightened focus on collective goals and outcomes (Markus and Kitayama 1991), we additionally examine the role of collective efficacy (Bandura 1997). Collective efficacy is the belief in the competence and capabilities of a group to perform a given behavior (Bandura 1997). While little marketing research to date has explored antecedents or consumption 
outcomes of collective efficacy (e.g., Ward and Ostrom 2006), its importance has been highlighted in contexts such as organizational leadership (Chen and Bliese 2002) and political action (Velasquez and LaRose 2015). Past work in the domain of sustainable behaviors demonstrates that collective efficacy is a stronger predictor of pro-environmental behaviors than individual self-efficacy (Chen 2015; Reese and Junge 2017). Given that an interdependent selfconstrual activates collective goals and outcomes, we posit that if collective-efficacy beliefs are low, crowdfunding participants' excitement about social-good products might be curbed. In essence, why seek the collective goal if there is no hope of achieving it? We expect that when collective efficacy is high, crowdfunding consumers will be motivated to pursue goal outcomes that benefit the collective, such as products that highlight the social good, yet when collectiveefficacy beliefs are low this will not be the case.

$\mathrm{H}_{4}$ : Within a crowdfunding transaction, consumer demand for social-good products will be lower (higher) when collective-efficacy beliefs are low (high).

\section{OVERVIEW OF STUDIES}

We test our predictions across six experiments. To show robustness of the effect, we operationalize consumer demand for social-good products differently across studies. The measures include actual willingness to pay for social-good products, relative preference scales, as well as actual consumer choice behavior of social-good versus self-benefit products. Studies 1A and $1 \mathrm{~B}$ examine $\mathrm{H}_{1}$ with real consumer behavior among individuals on a Canadian campus. Study 1A demonstrates that consumers are willing to pay more for a social-good product in a crowdfunding (vs. purchase) transaction. Study 1B extends the first study by replicating the focal effect (H1) and, at the same time, showing that it does not emerge for other products (i.e., self- 
benefit products). Building on these findings, Study $2 \mathrm{~A}$ again tests $\mathrm{H}_{1}$ but does so using a different dependent variable. In particular, participants are asked to make a choice between a social-good and self-benefit product, thus establishing that the focal crowdfunding effect also emerges in a relative choice paradigm and that the effect is indeed about social good. Study 2B tests the mediating role of self-construal and reveals that a crowdfunding (vs. purchase) transaction more strongly activates an interdependent self-construal, which helps to explain the increased consumer demand for social-good products among crowdfunding participants $\left(\mathrm{H}_{2}\right)$. It further rules out mediation via perceived risk, the role of others, and entrepreneurial need. Study 3 complements the prior studies by showing that the focal effect is attenuated when a previously crowdfunded product is already available for purchase in the marketplace $\left(\mathrm{H}_{3}\right)$. Finally, Study 4 demonstrates that within a crowdfunding transaction consumer demand for social-good products is reduced if consumers hold low (vs. high) collective-efficacy beliefs $\left(\mathrm{H}_{4}\right)$.

We next present the studies in more detail. For each experiment, all conditions and measures are reported, and any respective data exclusions are indicated. In initial studies we targeted a minimum of 80 participants per experimental cell, though in some in-person studies of real consumer behaviors (Studies 1A and 1B) participant availability (or lack thereof) altered final sample sizes slightly. As we became aware of the need to check for bot activity in online platforms, we targeted larger samples in each study and excluded failed checks consistently as available. Pre-registered studies are indicated as such, and detailed descriptions for all stimuli and pretests are available in the web appendix. 
Study 1 aims to provide an initial test of $\mathrm{H}_{1}$ in the context of actual consumer behaviors. Recall that in $\mathrm{H}_{1}$ we postulate that consumers in a crowdfunding versus purchase transaction will demonstrate a stronger demand for social-good products. In Study 1A we test this prediction by capturing consumers' willingness to pay for a social-good product. In Study 1B we contrast the willingness to pay for social-good products against self-benefit products.

\section{Study 1 A Method}

Participants and design. Participants were members of the general public who passed by a coffee shop on a Canadian university campus $(\mathrm{N}=160)$; they were $51 \%$ female, with an average age of $22.48(\mathrm{SD}=7.38) .{ }^{1}$ The study was a between-participants design with two transaction conditions: crowdfunding and purchase.

Procedure. A hypothesis-blind research assistant who was ostensibly representing a company with a prototype of a product—a pen — was situated at a table outside the coffee shop on campus. Signage on the table indicated that the product of interest was part of the Elements Reclaimed Pen Collection. The pen was clearly positioned in both conditions as supporting a social good (e.g., made from reclaimed materials; see web appendix), and there was no indication as to the type of transaction as participants approached the table (i.e., crowdfunding versus purchase) to eliminate selection bias. The research assistant invited passersby to try the new line of pens and offered them $\$ 2$ to participate in a short survey. The research assistant varied the transaction (i.e., crowdfunding vs. purchase) hourly. Once participants agreed to participate, the transaction manipulation was implemented with both verbal instructions (standardized) and the wording on the questionnaire itself. In the crowdfunding [purchase]

\footnotetext{
${ }^{1}$ We tested gender as a covariate in this and all subsequent studies and found that our treatment effects are robust both with and without gender included. We present analyses with gender as a covariate in the web appendix.
} 
condition respondents were told: "This is a prototype of a new pen, and we are crowdfunding financing for it [researching purchase interest] before producing it in larger numbers." Participants were given a pen to try out and a paper survey to complete. The survey first described the transaction, either crowdfunding or purchase, depending on assigned condition, which stated: "Today we are asking about your interest in crowdfunding [purchasing] a new product." The crowdfunding condition read: "In general, ideas for new goods and services of any kind can be realized if one has the funds to finance product development. As you might know, 'crowdfunding' refers to the consumer activity of funding the development of the final product. If enough funds are raised, the idea can be translated by the venture team into a new product. You then receive the product in return for your crowdfunding participation." Or alternatively, the purchasing condition: "In general, ideas for new goods and services of any kind can be realized if one has the funds to finance product development. If enough funds are raised, the idea can be translated by the venture team into a new product. As you might know, 'purchasing' refers to the consumer activity of acquiring the final product. You then receive the product in return for your payment." In both conditions participants read: "We are asking that you please carefully read the description of the new product below, examine the prototype of the product here today, and consider whether you would be interested in participating to crowdfund [interested in purchasing] the product."

Participants next read about the product and were told that they had the option to give part of their \$2 payment back and receive the pen in return. They were asked how much they would be willing to spend to crowdfund [purchase] the pen, in $\$ 0.25$ increments from $\$ 0$ to $\$ 2$. Finally, participants indicated their gender and age and then handed the survey and pen to the product representative (i.e., research assistant), who gave them the $\$ 2$ and an envelope, saying 
that if they wished to put some of their payment toward the pen, they should place the money in the envelope and give it to the representative. Those who put any amount of money in the envelope were given a pen to keep (i.e., there was no minimum price). The key dependent variable assessing consumer demand was the actual amount of money given to receive the pen. Study 1 A Results

All data were included in the analysis. In support of $\mathrm{H}_{1}$, we find that those in the crowdfunding condition paid significantly more money to obtain the social-good pen $(\mathrm{M}=$ $\$ 1.49, \mathrm{SD}=\$ .67)$ than did those in the purchase condition $\left(\mathrm{M}=\$ 1.05, \mathrm{SD}=\$ .70 ; \mathrm{t}_{158}=-4.04, p\right.$ $<.001, d=.62$ ). The findings thus provide evidence that when considering a social-good product, consumers are influenced in their actual payment decisions by whether the transaction is a crowdfunding or purchase exchange. In Study 1B we aim to replicate this effect and, at the same time, address the alternative explanation that a crowdfunding transaction might make consumers generally willing to pay more for any kind of product (not just social-good products). Study 1B Method

Participants and design. Participants were members of the general public who passed by a booth set up on a Canadian university campus $(\mathrm{N}=403$; they were $55 \%$ female, with an average age of $20.62, \mathrm{SD}=5.13)$. The study was a 2 (transaction: crowdfunding vs. purchase) $\times$ 2 (product type: social-good vs. self-benefit) between-participants design. The study design was pre-registered and is available at https://aspredicted.org/blind.php? $\mathrm{x}=\mathrm{eb} 4 \mathrm{n} 8 \mathrm{k}$.

Procedure. A hypothesis-blind research assistant who was ostensibly representing a company with a prototype of a product — a pen — was situated at a table. Signage on the table indicated that the product of interest was part of a collection of pens. The product was manipulated as either social-good (e.g., made from reclaimed materials) or self-benefit (e.g., 
performance quality; see web appendix for stimuli and pretest). The research assistant invited passersby to try the new line of pens and offered them $\$ 2$ to take a short survey-there were no indications of the transaction or product manipulations in order to eliminate selection bias in recruitment. The research assistant varied the transaction (i.e., crowdfunding vs. purchase) and pen collection (social-good vs. self-benefit) hourly, which was done with both verbal instructions (standardized) and the wording on the questionnaire itself once participants agreed to take part. The rotation of the hourly sessions was done in a random order each day of data collection to ensure that the condition varied by time of day. Specifically, the research assistant asked potential participants: "This is a prototype of a new pen. Would you be willing to complete a short 3-minute survey in return for \$2?” Those who agreed were then told that an effort was underway to crowdfund financing [research purchase interest] before producing the product in larger numbers, and they were given a pen to try out and a paper survey to complete. As in the previous study, the survey first gave an explanation of the transaction, either crowdfunding or purchase, depending on assigned condition (web appendix).

Participants next read about the product and were told that they had the option to give any amount of their $\$ 2$ payment back and receive the pen in return (i.e., again, there was no minimum price). They were asked how much they would be willing to spend to crowdfund [purchase] the pen, in $\$ 0.25$ increments from $\$ 0$ to $\$ 2$. Finally, participants indicated their gender and age then handed the survey and pen to the product representative (i.e., research assistant), who gave them the $\$ 2$ and an envelope, saying that if they wished to put some of their payment toward the pen, they should place the money in the envelope and give it to the representative. Those who put any amount of money in the envelope were given a pen to keep. The key 
dependent variable assessing consumer demand was again the actual amount of money given to receive the pen.

\section{Study $1 B$ Results}

All data were included in the analysis. A two-way ANOVA indicated a main effect of transaction $\left(\mathrm{F}(1,399)=4.95, p=.027, \eta_{\mathrm{p}}^{2}=.012\right)$, such that those in the crowdfunding condition paid significantly more money to obtain the pen $(\mathrm{M}=\$ 1.00, \mathrm{SD}=\$ .78)$ than did those in the purchase condition $(\mathrm{M}=\$ 0.83, \mathrm{SD}=\$ .80 ; \mathrm{t}(401)=-2.15, p=.032, d=.21)$. There was also a main effect of product type $\left(\mathrm{F}(1,399)=5.61, p=.018, \eta_{\mathrm{p}}{ }^{2}=.014\right)$, with participants willing to pay more for the social-good pen $(\mathrm{M}=\$ 1.01, \mathrm{SD}=\$ .81)$ than the self-benefit pen $(\mathrm{M}=\$ 0.83$, $\mathrm{SD}=\$ .77 ; \mathrm{t}(401)=-2.34, p=.020, d=.23)$. As anticipated, the interaction between transaction and product type was also significant $\left(\mathrm{F}(1,399)=10.51, p=.001, \eta_{\mathrm{p}}{ }^{2}=.026\right.$; Figure 1$)$. In support of $\mathrm{H}_{1}$, those in the crowdfunding condition demonstrated stronger demand for the socialgood product $(\mathrm{M}=\$ 1.22, \mathrm{SD}=\$ .77)$ than did those in the purchase condition $(\mathrm{M}=\$ .80, \mathrm{SD}=$ $\$ .80 ; \mathrm{F}(1,399)=14.84, p<.001, d=0.54)$. This effect was attenuated when the item was a selfbenefit product $\left(\mathrm{M}_{\text {crowdfund }}=\$ .79, \mathrm{SD}=\$ .74 ; \mathrm{M}_{\text {purchase }}=\$ .87, \mathrm{SD}=\$ .80 ; \mathrm{F}(1,399)=.521, p=\right.$ $.521, d=-.10)$. Looking at the data a different way, when the transaction was crowdfunding, participants paid more for the social-good pen $(\mathrm{M}=\$ 1.22, \mathrm{SD}=\$ .77)$ than the self-benefit pen $\left(\mathrm{M}=\$ 0.79, \mathrm{SD}=\$ .74 ; \mathrm{F}(1,399)=15.86, p<.001, \eta_{\mathrm{p}}^{2}=.038, d=.57\right)$. This difference was attenuated when it was a purchase transaction $\left(\mathrm{M}_{\text {social-good }}=\$ 0.80, \mathrm{SD}=\$ .80 ; \mathrm{M}_{\text {self-benefit }}=\$ 0.87\right.$, $\mathrm{SD}=\$ .80 ; \mathrm{F}(1,399)=.379, p=.539, d=-.08)$ 
FIGURE 1

\section{CROWDFUNDING INCREASES MONETARY CONTRIBUTIONS TO SOCIAL-GOOD BUT NOT SELF-BENEFIT PRODUCTS WHEN COMPARED TO PURCHASE}

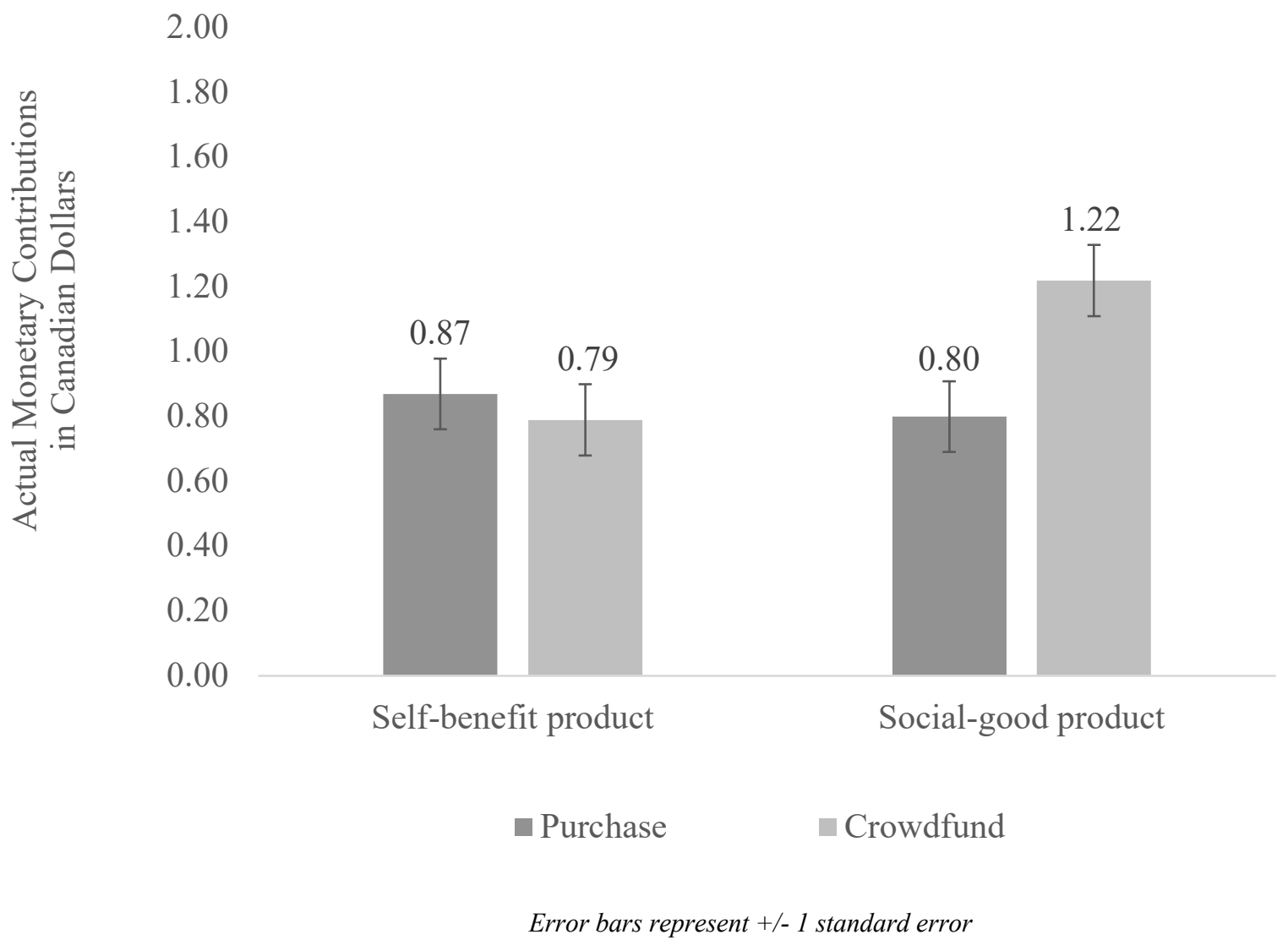

Discussion

Using consequential consumer behaviors, Studies $1 \mathrm{~A}$ and $1 \mathrm{~B}$ offer converging evidence that consumer spending decisions are impacted by whether the transaction is a crowdfunding or purchase exchange. In particular and consistent with $\mathrm{H}_{1}$, we find that consumers in a crowdfunding versus purchase transaction demonstrate a stronger demand for social-good products. Study 1B further calibrated this effect by demonstrating that the transaction manipulation did not affect consumer demand for self-benefit products. 
There is one alternative explanation possible with regard to this latter finding. In particular, the self-benefit product descriptions provided a suggested retail price $(\$ 2)$, while the social-good product descriptions did not (see web appendix). ${ }^{2}$ Hence, we need to ask whether this difference is a likely better explanation for the observed interaction (and in particular the attenuated effect for self-benefit products) compared to our theoretical account put forth. For example, one might argue that participants in the self-benefit conditions were anchored by the suggested retail price and did therefore not show any differences between transaction conditions. We believe this line of reasoning is unlikely to be at play in the current study. ${ }^{3}$ Nonetheless, we further address the calibration issue in Study 2. In particular, if crowdfunding similarly increased demand for both social-good and self-benefit products (which is the logical conclusion from the interpretation that the interaction found in this study is exclusively due to an anchoring effect), then we should not see any difference in consumer demand when participants are asked to make a choice between different types of products (social-good versus self-benefit).

\section{STUDIES $2 A$ AND $2 B$}

Study 2 first aims to further test $\mathrm{H}_{1}$ by capturing consumer demand in a relative fashion. In particular, participants are asked to make a choice between a social-good and self-benefit product, thus enabling us to test whether the focal crowdfunding effect also emerges in a relative choice paradigm and whether the effect is indeed about social good. In both Studies 2A and 2B

\footnotetext{
${ }^{2}$ This imbalance between product type conditions happened unknowingly to the researchers due to a version error in the stimuli. We thank an anonymous reviewer for pointing this out.

${ }^{3}$ First, participants in all conditions were "anchored" with $\$ 2$ because they were explicitly asked to think about how much of that amount (their compensation for having participated in the study) they were willing to give in exchange for receiving the product. Furthermore, if there was indeed only an anchoring effect going on, then the respective means in the self-benefit conditions should be closer to the anchor (\$2) than the ones in the social-good conditions where no anchor was provided. This was not the case. In contrast, both means in the purchase conditions are virtually identical $\left(\mathrm{M}_{\text {social-good }}=\$ 0.80 ; \mathrm{M}_{\text {self-benefit }}=\$ 0.87\right)$ while the means in the crowdfunding conditions show the opposite pattern $\left(\mathrm{M}_{\text {social-good }}=\$ 1.22 ; \mathrm{M}_{\text {self-benefit }}=\$ 0.79\right)$.
} 
participants are randomly assigned to either a crowdfunding or purchasing transaction, exposed to visual and verbal descriptions of two products, and asked about their product choice or preference. This direct-comparison experimental design is noted to have high statistical power and external validity (Meyvis and Van Osselaer 2018), and it has been used frequently in recent consumer research (e.g., Dahl, Fuchs, and Schreier 2015; Fuchs, Schreier, and van Osselaer 2015; Gunasti and Ross 2010; Newman and Dhar 2014). In Study 2A we use a consequential choice paradigm to test $\mathrm{H}_{1}$ (participants' choice would be real in the event that they win in a lottery). In Study 2B we assess consumer demand via a measure of preference and additionally test for the mediational role of self-construal $\left(\mathrm{H}_{2}\right)$. Finally, Study 2B tests perceived risk, the preferences of others, and entrepreneurial need as potential alternative explanations.

\section{Study 2 A Method}

Participants were undergraduate students from a large European university $(\mathrm{N}=244)$ who took part in an online study in exchange for course credit; they were $56 \%$ female, with an average age of $23.39(\mathrm{SD}=2.55)$. The experiment was a between-participants design in which participants were randomly assigned to either a crowdfunding or purchase transaction.

Participants were first told that the study was about crowdfunding [purchasing] new products. They were provided with information describing the transaction type similar to the previous studies (see web appendix). Both conditions next read: "On the following page we will introduce you to two new products available for you to consider crowdfunding [purchasing]. Attention: your decision might have consequences! In addition to the bonus points you receive as a compensation for participating in this study, you can win $€ 70$ in a lottery. In the event that you win, your decision indicated below will be real. This means you will be using the $€ 70$ won in the 
lottery to actually crowdfund [purchase] one of the two new products. If you win the lottery, which of these products would you crowdfund [purchase]?"

On the next screen, they read: "On the next page, please carefully read the descriptions of the two new products available for you to consider crowdfunding [purchasing].” Participants then saw a side-by-side comparison of two sunglasses products, one representing a social-good option (sunglasses made of recycled ghost fishing nets, i.e., abandoned nets that trap and kill fish and marine mammals) and one representing a self-benefit option (sunglasses with lenses that automatically adjust to the sunlight). The product information was counter-balanced in terms of both benefit dimension and product image and was successfully pretested on benefit dimensions (see web appendix). After studying the two types of sunglasses, participants read: "Please think back to the lottery that we told you about and consider which product you would crowdfund [purchase] if you won the lottery." They then indicated their product choice: "If you win the lottery, which option would you select?” $(0=$ Product from Start-up A and 1 = Product from Start-up B; data were recoded such that 1 represents choosing the social-good product, and 0 represents choosing the self-benefit product). The study design and analysis were pre-registered and are available at https://aspredicted.org/blind.php? $\mathrm{x}=\mathrm{zj} 8 \mathrm{sx} 9$.

\section{Study 2 A Results}

Product demand. We compared the share of participants who chose the social-good product versus self-benefit product as a function of transaction. Consistent with $\mathrm{H}_{1}$, significantly more participants chose the social-good product in the crowdfunding $(67.7 \%)$ versus purchase condition $\left(50.8 \% ; \chi^{2}=7.23, p=.007, d=.39\right)$. The odds of preferring the social-good product over the self-benefit product were 2.03 times as large in the crowdfunding than in the purchase condition $(\mathrm{OR}=2.03)$. Study $2 \mathrm{~A}$ thus further validates $\mathrm{H}_{1}$ : Consumers in a crowdfunding versus 
purchase transaction demonstrate a stronger demand for social-good products. Because product demand is captured in a relative fashion in this study, we can conclude that the effect is unique to social-good products and does not hold for self-benefit products.

\section{Study 2B Method}

Participants $(N=600)$ were recruited from Prolific Academic (www.prolific.ac) and were $71 \%$ female, with an average age of $32.98(\mathrm{SD}=11.56)$. The experiment again was a betweenparticipants design in which participants were randomly assigned to either a crowdfunding or purchase transaction and viewed the same information describing the transaction and stimuli as in Study 2A. In addition to the focal transaction information, participants read: "In this study we will show you two new products available for you to consider, and we are interested in which you might be most interested in crowdfunding [purchasing]." Prior to viewing the product stimuli, but after the transaction manipulation, participants completed four items measuring state self-construal (adapted from Chang and Hung 2018; Hamilton and Biehal 2005; Zhang and Khare 2009; all on 7-point bipolar scales; $\alpha=.86$ ): "Before showing you the two new products, we'd first like you to think about the context described - to what extent are you thinking about each of the following when you consider crowdfunding [purchasing] a product? (1) Right now, a sense of 'I' is at the top of my mind / Right now, a sense of 'we' is at the top of my mind, (2) I feel encouraged to think of myself / I feel encouraged to think of others, (3) I am thinking about myself as being independent of others / I am thinking about myself as being connected with others, (4) At this moment, I am focused on myself / At this moment, I am focused on others."

On the next screen, they read: "On the next page, please carefully read the descriptions of two new products available for you to consider crowdfunding [purchasing]." Participants then saw the same side-by-side comparison of two sunglasses products as in Study 2A. After studying 
the two types of sunglasses, participants read: "Please think back to the information you have been provided and consider which product you would crowdfund [purchase] if you had to make a real decision at this time." They then completed the dependent variable: "Which of these options would you select?" ( 1 = definitely select the product from Start-up A and 7 = definitely select the product from Start-up B; data were recoded such that a higher score represents a stronger demand for the social-good product).

Additionally, to examine other potential explanations for the effect, we asked participants to indicate their answers to: "I think there is considerable risk involved in choosing the product of this start-up; I believe others will be inclined to choose the product of this start-up; I believe the entrepreneurs behind the start-up need financial support; and, I think the entrepreneurs behind the start-up should be supported because they are more in need" (all 7-point scales where $1=$ more true for Start-up A and 7 = more true for Start-up B). Finally, we captured participants' gender and age, as well as a bot check/attention question. The study design and analysis were pre-registered and are available at $\mathrm{https://aspredicted.org/blind.php? \textrm {x } = 2 8 \mathrm { ey } 3 \mathrm { c } .}$

\section{Study $2 B$ Results and Discussion}

A total of 13 participants failed the bot/attention check and thus were excluded from the analysis (final $\mathrm{N}=587$ ).

Product demand. In support of $\mathrm{H}_{1}$, we find that participants in the crowdfunding condition demonstrate a significantly stronger demand for the social-good versus self-benefit product $(\mathrm{M}=5.13 \mathrm{SD}=1.97)$ compared to those in the purchase condition $(\mathrm{M}=4.29, \mathrm{SD}=$ $\left.2.08 ; \mathrm{t}_{585}=-4.98, p<.001, d=.41\right)$.

Self-construal. As predicted $\left(\mathrm{H}_{2}\right)$, the transaction manipulation also impacted selfconstrual. In particular, we find that participants in the crowdfunding condition described a more 
pronounced activation of an interdependent mindset $(\mathrm{M}=4.35, \mathrm{SD}=1.39)$ compared to those in the purchase condition $\left(\mathrm{M}=3.64, \mathrm{SD}=1.52 ; \mathrm{t}_{585}=-5.95, p<.001, d=.49\right)$.

Mediation. Mediation was tested using Process Model 4 (Hayes 2018). Results indicate that the indirect effect of transaction on product demand through self-construal was significant (b $=.12, \mathrm{SE}=.05, \mathrm{CI}: .025$ to .225$)$.

Alternative explanations. We conducted additional contrasts to examine the other potential mediators collected. None of the contrasts were significant ( $p$ 's all > .34).

\section{Discussion}

Studies 2A and 2B provide convergent evidence in support of $\mathrm{H}_{1}$. Employing relative choice paradigms, we find that consumers in crowdfunding transactions demonstrate stronger demand for social-good (vs. self-benefit) products compared to consumers in purchase transactions. The focal crowdfunding effect is hence unique to social-good products. Study $2 \mathrm{~B}$ further validates $\mathrm{H}_{2}$ : The effect is mediated by self-construal such that a crowdfunding (vs. purchase) transaction activates a more interdependent self-construal. Finally, we provide evidence that the focal effect does not appear to be due to perceived risk, the potential choices of others, or entrepreneurial need perceptions.

\section{STUDY 3}

The previous studies demonstrate the increased demand for social-good products as a function of a crowdfunding versus purchase transaction $\left(\mathrm{H}_{1}\right)$; yet there remain additional considerations regarding crowdfunding more specifically. As detailed in $\mathrm{H}_{3}$, we predict that the focal effect on one's demand for social-good products is attenuated when a previously 
crowdfunded product is available for purchase. We test this prediction in Study 3 by adding the respective condition to the previously employed crowdfunding and purchase conditions (i.e., purchase of a previously crowdfunded product). We predict a significant difference in consumer demand for social-good products between the crowdfunding and both the purchase condition and the purchase with crowdfunding history condition. We do not anticipate any differences between the latter two conditions. We pre-registered these predictions prior to data collection (see https://aspredicted.org/blind.php? $\mathrm{x}=\mathrm{nn} 89 \mathrm{fb})$. A pretest provided initial support for our theorizing, revealing a hypothesis-consistent pattern of effects with regard to perceptions of selfconstrual and providing additional support for $\mathrm{H}_{2}$ (see web appendix for details).

\section{Method}

Participants were recruited from Prolific $(\mathrm{N}=1,214)$, and those that failed a bot check were removed $(\mathrm{N}=65)$ from the analysis, resulting in a final sample of $1,149\left(70 \%\right.$ female; $\mathrm{M}_{\text {age }}$ $=34.41, \mathrm{SD}=11.11)$. The experiment was a between-participants design with three transaction conditions randomly assigned: crowdfunding versus purchase versus purchase with crowdfunding history. The first two conditions used descriptions similar to those in previous studies (see web appendix). In contrast, participants in the third condition (purchase with crowdfunding history) read the following: "In this study we will show you two new products for you to consider that were financed through crowdfunding and are now available to purchase, and we are interested in which one you might be most interested in purchasing."

After the transaction manipulation all participants saw the same visual and verbal descriptions of two pairs of sunglasses that counter-balanced social-good and self-benefit dimensions as in Studies 2A and 2B. They were asked which of these products they would be most interested in crowdfunding/purchasing $(1=$ "definitely crowdfund/purchase the product 
from Start-up A, to 7 = definitely crowdfund/purchase the product from Start-up B"). Data were recoded such that a higher score represents stronger demand for the social-good product. Participants completed a bot/attention check (as in Study 2B) and reported their gender and age. Results

An ANOVA on our dependent measure with transaction as independent variable indicates significant differences between conditions $\left(\mathrm{F}(2,1146)=4.74, p=.009, \eta_{\mathrm{p}}{ }^{2}=.008\right)$. In particular, we find that participants in the crowdfunding condition demonstrate a significantly stronger demand for the social-good versus self-benefit product $(\mathrm{M}=5.20, \mathrm{SD}=2.03)$ compared to those in the purchase condition $\left(\mathrm{M}=4.88, \mathrm{SD}=2.08 ; \mathrm{t}_{765}=-2.14, p=.032, d=.16\right)$. This once again validates $\mathrm{H}_{1}$. More central to the aims of this study, we also find that participants in the crowdfunding condition reported a stronger demand for the social-good product than did those in the purchase with a crowdfunding history condition $\left(\mathrm{M}=4.75, \mathrm{SD}=2.06 ; \mathrm{t}_{762}=3.01, p\right.$ $=.003, d=.22)$. There was no significant difference in our dependent variable between the purchase and purchase with crowdfunding history conditions ( $\left.\mathrm{t}_{765}=.847, p=.397, d=.06\right)$.

Validating $\mathrm{H}_{3}$, these findings imply that the increased demand for social-good products emerges as a function of actually engaging in the crowdfunding process rather than because the product has been developed through crowdfunding. The mere mention of being developed via crowdfunding, then, is not enough to activate the effect. Put differently, the focal effect reported in this research is contingent on actual crowdfunding participation: It is attenuated when a previously crowdfunded product is already available for purchase. 
In Study 4, we test whether within crowdfunding consumer demand for social-good products will be lower (higher) when collective-efficacy beliefs are low (high) $\left(\mathrm{H}_{4}\right)$. We argue that the effect of a shift in mindset caused by crowdfunding (toward a more interdependent selfconstrual) will lose its impact when one holds low collective-efficacy beliefs (e.g., "we cannot likely bring about change by working together"). To further calibrate the insight, we employ product type between-participants (both social-good and self-benefit products; similar to Study 1B). In particular, we reason that collective efficacy should more strongly affect consumer demand for social-good as opposed to self-benefit products. Participants are asked how much of a $\$ 2$ payment they would spend to crowdfund the focal product. To be parsimonious, we ran the study within crowdfunding only — that is, we did not include any purchase conditions but instead devised a 2 (product type: social-good vs. self-benefit) $\times 2$ (collective efficacy: low vs. high) between-participants experiment. ${ }^{4}$

\section{Method}

Participants $(\mathrm{N}=1,242)$ were recruited from Amazon's Mechanical Turk. Consistent with previous studies and determined prior to data collection, those that failed a bot check $(\mathrm{N}=$ $279)^{5}$ were removed. The resulting participants $(\mathrm{N}=963)$ were $49 \%$ female, with an average age of $35.75(\mathrm{SD}=11.48)$. As indicated, the experiment had a 2 (product type: social-good vs. selfbenefit) $\times 2$ (collective efficacy: low vs. high) between-participants design. All participants were provided with an introduction to a crowdfunding transaction similar to earlier studies (see web appendix), and then read that they would be exposed to a new product available to crowdfund

\footnotetext{
${ }^{4}$ We note that it is theoretically less interesting to consider the effects of collective-efficacy beliefs in a classic purchase transaction. This is because the product is already to market in the purchase condition, so collectiveefficacy beliefs do not really apply here and thus we focused on a crowdfunding transaction.

${ }^{5}$ While this study employed the same attention/bot check as earlier studies, we note that the number of failed participants is higher. We attribute this to the use of a captcha on the study consent page in our other online studies, which was not done in this study.
} 
and asked to consider whether they would support it. The focal product was a pen, and the product-type manipulation was similar to the one used in Study 1 (see web appendix). Participants were further told that one aspect of the study was examining the effect of interruptions on decision-making, so after considering the product they would be interrupted with an additional task.

After viewing the product stimuli, participants were asked to read a statement about research supporting (high collective efficacy) or downplaying (low collective efficacy) the effectiveness of collective action. For example, "Surprisingly, new research demonstrates that most often the common goal is actually within [out of] reach! That is, although [because] often many of the problems faced are so large and profound, [even] collectively we really can [cannot] bring about change and [nor] make a meaningful difference! The title and also the conclusion from this research is: "Doing Good and Really Getting Somewhere [Doing Good without Getting Anywhere]." They were then asked to write "one solid reason in support of the core idea underlying the research" they had read about. Following this manipulation, participants were again shown the product descriptions and demand was assessed via how much of a potential $\$ 2$ lottery winning they would be willing to spend to participate in crowdfunding the pen and subsequently receive a prototype of the pen via mail.

Participants also completed two manipulation checks: "Please think about the pen shown to you. Which is more appropriate?" (7-point scale, $1=$ the pen provides good benefits to me [i.e., allows smooth writing], $7=$ the pen provides social benefits to society [i.e., helps to make the world a better place]); and, "When you think about collective action, how likely is it that we can bring change and solve big problems?" (7-point scale, 1 = collective action can really get us 
somewhere, 7 = collective action cannot really get us anywhere; reverse-coded). Finally, participants indicated their age and gender, and completed the bot-check from previous studies. Results and Discussion

Manipulation checks. Findings of manipulation checks reveal that the social-good penon average and across conditions - was perceived as providing greater social benefits. Participants who saw the pen positioned as a social-good product rated it significantly higher than the scale midpoint on the social-good manipulation-check item $\left(\mathrm{M}_{\text {social-good }}=5.57, \mathrm{SD}=\right.$ $\left.1.47 ; \mathrm{t}_{475}=23.38, p<.001, d=1.08\right)$. In contrast, those in the self-benefit condition rated the pen as providing greater benefits to the self significantly lower than the scale midpoint $\left(\mathrm{M}_{\text {self-benefit }}=\right.$ $\left.2.32, \mathrm{SD}=1.59 ; \mathrm{t}_{486}=-23.31, p<.001, d=1.05\right)$. Additionally, those in the high collectiveefficacy condition were more inclined to indicate that collective action can enact change ( $\mathrm{M}_{\mathrm{CE} \text { high }}$ $=5.90, \mathrm{SD}=1.42)$ than were those in the low collective-efficacy condition $\left(\mathrm{M}_{\mathrm{CE} \text { low }}=4.54, \mathrm{SD}=\right.$ $\left.1.77 ; \mathrm{t}_{897}=-13.18, p<.001, d=.85\right)$. Thus, the manipulations of both product type and collective efficacy were successful. We conducted additional analyses on all conditions and report these in the web appendix.

Monetary contributions. Replicating results obtained in Study 1B, a main effect of product type $\left(\mathrm{F}(1,959)=20.14, p<.001, \eta_{\mathrm{p}}{ }^{2}=.021\right)$ revealed that consumers were willing to contribute a significantly greater portion of their potential lottery payment to crowdfund the social-good pen $(\mathrm{M}=\$ .64, \mathrm{SD}=\$ .68)$ than the self-benefit pen $\left(\mathrm{M}=\$ .45, \mathrm{SD}=\$ .64\right.$; $\mathrm{t}_{954}=-$ $4.50, p<.001, d=.29)$. No main effect for collective efficacy emerged $(\mathrm{F}(1,959)=1.20, p=$ $\left..274, \eta_{\mathrm{p}}{ }^{2}=.001\right)$. Additionally, there was a significant interaction between product type and collective efficacy $\left(\mathrm{F}(1,959)=4.74, p=.030, \eta_{\mathrm{p}}{ }^{2}=.005\right.$; Figure 2$)$. When this belief was high, participants strongly preferred the social-good pen $(\mathrm{M}=\$ .71, \mathrm{SD}=\$ .71)$ over the self-benefit 
pen $(\mathrm{M}=\$ .42, \mathrm{SD}=\$ .63 ; \mathrm{F}(1,959)=22.80, p<.001, d=.43)$. However, when collectiveefficacy belief was low, this difference was mitigated $\left(\mathrm{M}_{\text {social-good }}=\$ .57, \mathrm{SD}=\$ .65 ; \mathrm{M}_{\text {self-benefit }}=\right.$ $.47, \mathrm{SD}=.65 ; \mathrm{F}(1,959)=2.60, p=.107, d=.15)$. Additional contrasts revealed that monetary contributions were significantly greater for those in the social-good pen condition when belief in collective efficacy was high $\left(\mathrm{M}_{\mathrm{CE} \text { high }}=\$ .71, \mathrm{SD}=\$ .71\right)$ than when it was low $\left(\mathrm{M}_{\mathrm{CE} \text { low }}=\$ .57\right.$, $\mathrm{SD}=\$ .65 ; \mathrm{F}(1,959)=5.31, p=.021, d=.21)$; yet, as we intuited, the collective-efficacy manipulation had little impact when the product was focused on self-benefits $\left(\mathrm{M}_{\mathrm{CE} \text { high }}=\$ .42\right.$, $\left.\mathrm{SD}=\$ .63 ; \mathrm{M}_{\mathrm{CE} \text { low }}=\$ .47, \mathrm{SD}=\$ .65 ; \mathrm{F}(1,959)=.59, p=.441, d=.07\right)$.

\section{FIGURE 2}

\section{CROWDFUNDING LOSES ITS IMPACT ON CONSUMERS' DEMAND FOR SOCIAL- GOOD PRODUCTS WHEN COLLECTIVE-EFFICACY BELIEFS ARE LOW}

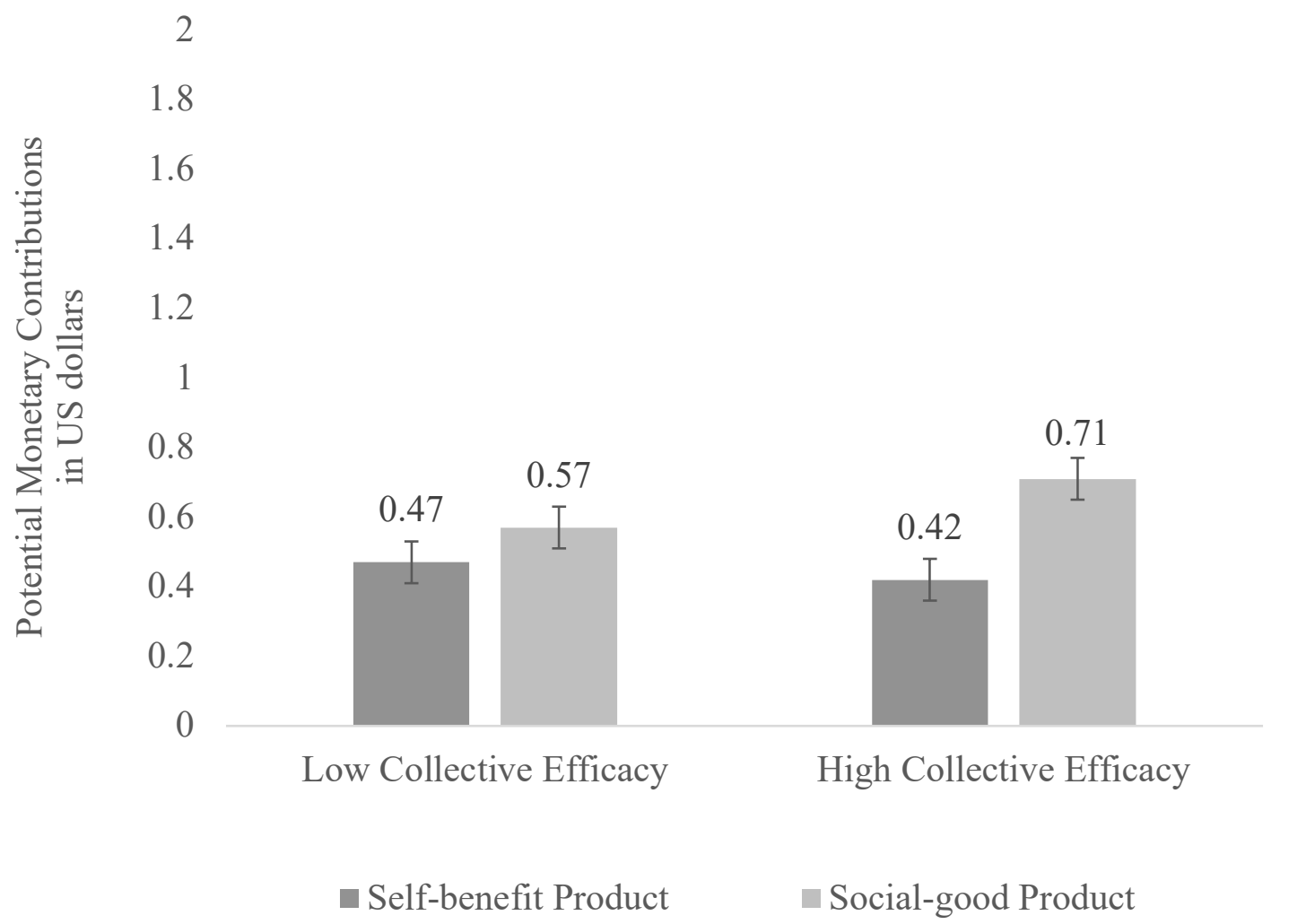


Study 4 provides evidence for $\mathrm{H} 4$ by showing that within crowdfunding demand for social-good products is lower (higher) when consumers hold low (high) collective-efficacy beliefs. Put differently, crowdfunding loses its impact when one holds low collective-efficacy beliefs (e.g., "we cannot likely bring about change by working together"). In addition, the study shows that collective efficacy does not affect consumer demand for self-benefit products. The study therefore adds a richer understanding of when and why consumers will demonstrate greater demand for social-good products when crowdfunding.

\section{GENERAL DISCUSSION}

Across six studies we demonstrate that consumer demand for social-good products increases when crowdfunding versus purchasing, and that this effect is driven (at least in part) by the activation of an interdependent self-construal. Our research derives these robust findings from real behavioral outcomes, in campus consumer choices (Studies 1A and 1B) and online environments (Study 2A), and from online preferences (Studies 2B, 3-4), while using a variety of product stimuli and construct operationalizations. Moreover, we use a range of both general consumer and student participant samples from different nationalities. We demonstrate the effect with a range of dependent variables to assess consumer demand including dichotomous consumer choice, actual payment amounts, and measured consumer preferences.

\section{Theoretical Implications of the Research}

This research presents the first systematic analysis of the implications that offering products via crowdfunding (vs. for purchase) may have for the consumer's decision-making process. In doing so, we offer a conceptual framework elucidating why consumers make different product choices as a function of the transaction type (i.e., crowdfunding vs. purchase), 
adding to the limited work on the psychological consequences of crowdfunding. Moreover, we demonstrate that a crowdfunding transaction activates a more interdependent self-construal. This is an important finding because consumer research has widely explored consequences of selfconstrual, yet it has given little attention to understanding what natural marketplace characteristics (beyond language priming; e.g., Simpson, White, and Laran 2018; White and Simpson 2013) might activate an individual's independent or interdependent self-construal. Indeed, while the crowdfunding literature has seen some consideration of self-construal (via cultural similarity) as an antecedent to lending (Burtch, Ghose, and Wattal 2013), it has not been considered as an outcome of crowdfunding transactions.

The current research also builds on previous literature that considers psychological motivations underlying crowdfunding (Kuppuswamy and Bayus 2017; Zvilichovsky, Danzinger, and Steinhart 2018) highlighting that prosocial motivations need not necessarily exist prior to the decision to crowdfund to have impact but in fact may emerge as a function of the transaction itself. Thus while literature demonstrates that crowdfunding participants are motivated by their potential impact to make a product happen (i.e., helping bring projects into the world that otherwise would not exist; Dai and Zhang 2019; Kuppuswamy and Bayus 2017; Zvilichovsky, Danzinger, and Steinhart 2018), we suggest that our construal-level account enhances our understanding about which product a consumer might more strongly want to help develop.

This work also extends theorizing in consumer research by revealing that consumers' low collective-efficacy beliefs can attenuate social-good product demand in a crowdfunding transaction, delivering an empirical examination of collective efficacy not tested before in the consumer literature. This provides an important consideration for the construct of collective efficacy in consumption domains, which has received scant attention in marketing research. 


\section{Practical Implications and Directions for Future Research}

Our focal finding - that compared to classic purchase transactions, crowdfunding can heighten consumer demand for social-good products - has practical contributions for ventures launching new products. Our results suggest that for products associated with a greater level of social good, ventures may want to consider using a crowdfunding platform to launch their products, as it may provide them with an advantage relative to a traditional purchase transaction. In other words, consumers will likely be more inclined to obtain social good products when they are offered through crowdfunding rather than purchase. Building on research suggesting that crowdfunding campaigns can heighten consumer identification with the venture (Bitterl and Schreier 2018), our findings indicate that a product launch via crowdfunding rather than purchase is a worthwhile consideration for social-good products in particular.

The current research contrasts crowdfunding and purchase transactions. It is worth noting that there are other transaction types that may similarly involve prosocial elements or a sense of shared social responsibility. For instance, pay-it-forward pricing (Gneezy et al. 2010; Jung et al. 2014, 2017) and cause-marketing associated with a gift (Zlatev and Miller 2016) both entail some aspect of a purchase exchange that carries social benefit. It may be valuable to consider to what extent each of these transaction types might activate an interdependent self-construal. At first glance, it would seem that the collective nature of crowdfunding may be more explicit than those types of transactions in activating the salience of connectedness with others and collective goals. Thus, it remains to be seen whether pay-it-forward pricing and cause-marketing would similarly shift consumer self-construal.

For those ventures that have already decided to use crowdfunding to fund and/or market their new product, our research indicates that emphasizing the social-good aspects of the product 
in their project pitch will increase the likelihood of success. Such ventures should avoid the activation of an independent self-construal or information that might mitigate collective-efficacy beliefs. Such information could lead to backfire effects, wherein consumers may be less likely to select social-good options. The activation of an interdependent self-construal may warrant additional considerations, however, given that literature highlights a range of consequences of doing so, as discussed in the theoretical review above. For those launching via crowdfunding and highlighting interdependence at the same time, it might be relevant to consider other elements such as minimizing social risk (Mandel 2003) and positioning with prevention- (vs. promotion)focused information (Aaker and Lee 2001). Future research can explore these possibilities.

The above implications also raise questions about what other attributes, beyond social good, might possibly be perceived more positively in crowdfunding transactions. For instance, it might be that a highly innovative product could drive similar effects. In addition to receiving self-benefit from a highly innovative product, consumers might be motivated to 'make the world a better place' by helping the innovative idea hit the broader market. Innovative products, in particular, could be seen as having high potential to make a meaningful collective impact to society that might be augmented in crowdfunding transactions. This is speculative, however, and further research is needed to claim (or refute) this with more certainty.

Beyond product demand, it might also be possible that consumers would perceive an organization engaged in crowdfunding more positively because they may view the firm as contributing to a social good by facilitating collective goals, and such social goodwill can translate into positive consumer perceptions (Chernev and Blair 2015). This would align with research documenting that members of collectivistic cultures tend to make more altruistic attributions about CSR motives of companies (Choi et al. 2016). Thus, research could consider 
constructs beyond product demand, looking at how crowdfunding might impact consumer perceptions at a brand or firm level.

Future research might also investigate how consumer characteristics and product types may moderate our focal effect. While our effects were obtained primarily with general consumer populations who were randomly assigned to experimental conditions, one question is whether certain consumers are more attracted to crowdfunding than others. For instance, might those with a more highly interdependent self-construal as an individual difference be more drawn to such platforms? Many promising research avenues stem from the current research, and we hope that this work spurs additional researchers to examine the consequences of crowdfunding from a consumer perspective. 


\section{REFERENCES}

Aaker, Jennifer L. and Angela Y. Lee (2001), “'I’ Seek Pleasures and 'We' Avoid Pains: The Role of Self-Regulatory Goals in Information Processing and Persuasion," Journal of Consumer Research, 28 (1), 33-49.

Agrawal, Ajay, Christian Catalini, and Avi Goldfarb (2015), "Crowdfunding: Geography, Social Networks, and the Timing of Investment Decisions," Journal of Economics and Management Strategy, 24 (2), 253-74.

Agrawal, Nidhi and Durairaj Maheswaran (2005), “The Effects of Self-Construal and Commitment on Persuasion," Journal of Consumer Research, 31 (4), 841-49.

Allison, Thomas H., Blakley C. Davis, Jeremy C. Short, and Justin W. Webb (2015), "Crowdfunding in a Prosocial Microlending Environment: Examining the Role of Intrinsic Versus Extrinsic Cues,” Entrepreneurship Theory \& Practice, 39 (1), 53-73.

Arnocky, Steven, Mirella Stroink, and Teresa DeCicco (2007), "Self-construal Predicts Environmental Concern, Cooperation, and Conservation," Journal of Environmental Psychology, 27 (4), 255-64.

Bandura, Albert (1997), Self-efficacy: The Exercise of Control. New York: WH Freeman/Times Books/Henry Holt \& Co.

Belleflamme, Paul, Thomas Lambert, and Armin Schwienbacher (2014), “Crowdfunding: Tapping the Right Crowd," Journal of Business Venturing, 29 (5), 585-609.

Bitterl, Sally and Martin Schreier (2018), "When Consumers Become Project Backers: The Psychological Consequences of Participation in Crowdfunding," International Journal of Research in Marketing, 35 (4), 673-85. 
Blaseg, Daniel, Christian Schulze, and Bernd Skiera (2020), "Consumer Protection on Kickstarter," Marketing Science, https://doi.org.10.1287/mksc.2019.1203

Brewer, Marilynn and Wendi Gardner (1996), "Who Is This 'We'? Levels of Collective Identity and Self Representations," Journal of Personality and Social Psychology, 71 (1), 83-93.

Briley, Donnel A. and Robert S. Wyer, Jr. (2001), “Transitory Determinants of Values and Decisions: The Utility (or Nonutility) of Individualism and Collectivism in Understanding Cultural Differences," Social Cognition, 19 (3), 197-227.

Brown, Terrence E., Edward Boon, and Leyland F. Pitt (2017), "Seeking Funding in Order to Sell: Crowdfunding as a Marketing Tool,” Business Horizons, 60 (2), 189-95.

Burtch, Gordon, Anindya Ghose, and Sunil Wattal (2013), "An Empirical Examination of the Antecedents and Consequences of Investment Patterns in Crowd-Funded Markets," Information Systems Research, 24 (3), 499-519.

Burton, K. Alex, Jonathan S. Gore, and Jennifer Sturgeon (2012), "The Role of Relational Selfconstrual in Reactions to Charity Advertisements," Self and Identity, 11 (3), 343-59.

Calic, Goran and Elaine Mosakowski (2016), "Kicking Off Social Entrepreneurship: How a Sustainability Orientation Influences Crowdfunding Success," Journal of Management Studies, 53 (5), 738-67.

Chang, Hannah H. and Iris W. Hung (2018), "Mirror, Mirror on the Retail Wall: Self-Focused Attention Promotes Reliance on Feelings in Consumer Decisions," Journal of Marketing Research, 55 (4), 586-99.

Chen, Gilad and Paul D. Bliese (2002), “The Role of Different Levels of Leadership in Predicting Self- and Collective Efficacy: Evidence for Discontinuity," The Journal of Applied Psychology, 87 (3), 549-56. 
Chen, Mei-Fang (2015), "Self-Efficacy or Collective Efficacy Within the Cognitive Theory of Stress Model: Which More Effectively Explains People's Self-Reported Proenvironmental Behavior?" Journal of Environmental Psychology, 42, 66-75.

Chernev, Alexander and Sean Blair (2015), "Doing Well by Doing Good: The Benevolent Halo of Corporate Social Responsibility," Journal of Consumer Research, 41 (6), 1412-25.

Choi, Jungsil, Young Kyun Chang, Yexin Jessica Li, and Myoung Gyun Jang (2016), “Doing Good in Another Neighborhood: Attributions of CSR Motives Depend on Corporate Nationality and Cultural Orientation," Journal of International Marketing, 24 (4), 82 104.

Chuang, Yating, Xiaofei Xie, and Chang Liu (2016), “Interdependent Orientations Increase Proenvironmental Preferences when Facing Self-interest Conflicts: The Mediating Role of Self-control," Journal of Environmental Psychology, 46 (June), 96-105.

Dahl, Darren W., Christoph Fuchs, and Martin Schreier (2015), "Why and When Consumers Prefer Products of User-Driven Firms: A Social Identification Account," Management Science, 61 (8), 1978-88.

Dai, Hengchen and Dennis J. Zhang (2019), "Prosocial Goal Pursuit in Crowdfunding: Evidence from Kickstarter," Journal of Marketing Research, 56 (3), 498-517.

Downie, Michelle, Richard Koestner, Elizabeth Horberg, and Silje Haga (2006), "Exploring the Relation of Independent and Interdependent Self-Construals to Why and How People Pursue Personal Goals," The Journal of Social Psychology, 146 (5), 517-31.

Duclos, Rod and Alixandra Barasch (2014), "Prosocial Behavior in Intergroup Relations: How Donor Self-Construal and Recipient Group-Membership Shape Generosity,” Journal of Consumer Research, 41 (1), 93-108. 
Fuchs, Christoph, Martin Schreier, and Stijn M.J. van Osselaer (2015), "The Handmade Effect: What's Love Got to Do with It," Journal of Marketing, 79, 98-110.

Galak, Jeff, Deborah Small, and Andrew T. Stephen (2011), "Microfinance Decision Making: A Field Study of Prosocial Lending," Journal of Marketing Research, 48, 130-37.

Gallaga, Omar (2013), "Hooked on Kickstarter: It’s Just Another Way to Shop Online” (accessed August 13, 2018) [https://www.ajc.com/technology/hooked-kickstarterjustanother-way-shop-online/9NfsJHH6mQVbPgsyt58vaK/].

Gerber, Elizabeth and Julie Hui (2016), "Crowdfunding: How and Why People Participate," in Jerome Méric, Isabelle Maque, and Julienne Brabet (Eds.), International Perspectives on Crowdfunding: Positive, Normative and Critical Theory, Emerald, UK, 37-64.

Gneezy, Ayelet, Uri Gneezy, Leif D. Nelson, and Amber Brown (2010), "Shared Social Responsibility: A Field Experiment in Pay-What-You-Want Pricing and Charitable Giving," Science, 329 (5989), 325-27.

Gubler, Zachary J. (2013), “Inventive Funding Deserves Creative Regulation,” Wall Street Journal, January 31 . http://online.wsj.com/article/SB10001424127887323468604578251913868617572.html.

Gunasti, Kunter and William T. Ross, Jr. (2010), "How and When Alphanumeric Brand Names Affect Consumer Preferences," Journal of Marketing Research, 47 (6), 1177-92.

Hamilton, Rebecca W. and Gabriel J. Biehal (2005), “Achieving Your Goals or Protecting Their Future? The Effects of Self-View on Goals and Choices," Journal of Consumer Research, 32 (2), 277-83.

Hayes, Andrew F. (2018), Introduction to Mediation, Moderation, and Conditional Process Analysis: A Regression-based Approach, $2^{\text {nd }}$ edition. New York: Guilford Press. 
Hong, Jiewen and Hannah H. Chang (2015), “'I' Follow My Heart and 'We' Rely on Reasons:

The Impact of Self-Construal on Reliance on Feelings versus Reasons in Decision Making," Journal of Consumer Research, 41 (6), 1392-1411.

Jung, Minah H., Leif Nelson, Uri Gneezy, and Ayelet Gneezy (2014), “Paying More When

Paying for Others," Journal of Personality and Social Psychology, 107 (3), 414-31.

Jung, Minah, Leif Nelson, Uri Gneezy, and Ayelet Gneezy (2017), “Signaling Virtue: Charitable

Behavior Under Consumer Elective Pricing,” Marketing Science, 36 (2), 187-94.

Kühnen, Ulrich and Bettina Hannover (2000), “Assimilation and Contrast in Social Comparisons as a Consequence of Self-Construal Activation," European Journal of Social Psychology, 30, 799-811.

Kuppuswamy, Venkat and Barry L. Bayus (2017), "Does My Contribution to Your Crowdfunding Project Matter?” Journal of Business Venturing, 32 (1), 72-89.

Lalwani, Ashok K. and Sharon Shavitt (2013), "You Get What You Pay For? Self-Construal Influences Price-Quality Judgements," Journal of Consumer Research, 40 (2), 255-67.

Mandel, Naomi (2003), "Shifting Selves and Decision Making: The Effects of Self-Construal Priming on Consumer Risk-Taking," Journal of Consumer Research, 30 (1), 30-40.

Markus, Hazel Rose and Shinobu Kitayama (1991), “Culture and the Self: Implications for Cognition, Emotion, and Motivation," Psychological Review, 98 (2), 244-53.

Meyvis, Tom and Stijn M. Van Osselaer (2018), "Increasing the Power of Your Study by Increasing the Effect Size," Journal of Consumer Research, 44 (5), 1157-73. Mollick, Ethan (2014), “The Dynamics of Crowdfunding: An Exploratory Study,” Journal of Business Venturing, 29 (1), 1-16. 
Mollick, Ethan (2018), "The Unique Value of Crowdfunding Is Not Money_-It's Community," Harvard Business Review, April 21. https://hbr.org/2016/04/the-unique-value-ofcrowdfunding-is-not-money-its-community

Moorman, Robert H. and Gerald L. Blakely (1995), "Individualism-collectivism as an Individual Difference Predictor of Organizational Citizenship Behavior,” Journal of Organizational Behavior, 16 (2), 127-42.

Newman, George E. and Ravi Dhar (2014), “Authenticity Is Contagious: Brand Essence and the Original Source of Production," Journal of Marketing Research, 51 (3), 371-86.

Obhi, Sukhvinder, S., Jeremy Hogeveen, and Alvaro Pascual-Leone (2011), "Resonating with Others: The Effects of Self-construal Type on Motor Cortical Output," Journal of Neuroscience, 31 (41), 14531-535.

Pew Research Center's American Trends Panel Wave 13 (2015). Dataset retrieved February 20, 2019, from: http://www.pewinternet.org/dataset/american-trends-panel-wave-13/

Pietraszkiewicz, Agnieszka, Birthe Soppe, and Magdalena Formanowicz (2017), "Go Pro Bono," Social Psychology, 48 (5), 265-78.

Reese, Gerhard and Eva A. Junge (2017), “Keep on Rockin’ in a (Plastic-)Free World: Collective Efficacy and Pro-Environmental Intentions as a Function of Task Difficulty," Sustainability, 9 (2), 200.

Ryu, Sunghan and Young-Gul Kim (2016), “A Typology of Crowdfunding Sponsors: Birds of a Feather Flock Together?” Electronic Commerce Research and Applications, 16, 43-54. Shavitt, Sharon, Angela Y. Lee, and Timothy P. Johnson (2008), “Cross-Cultural Consumer Psychology," in C. Haugtvedt, P. Herr, and F. Kardes (Eds.), Handbook of Consumer Psychology (pp. 1103-32), New York: Psychology Press. 
Simpson, Bonnie, Jennifer Robertson, and Katherine White (2019), "How Co-creation Increases Employee Corporate Social Responsibility and Organizational Engagement: The Moderating Role of Self-Construal," Journal of Business Ethics. https://doi.org/10.1007/s10551-019-04138-3

Simpson, Bonnie, Katherine White, and Juliano Laran (2018), "When Public Recognition for Charitable Giving Backfires: The Role of Independent Self-Construal,” Journal of Consumer Research, 44 (6), 1257-73.

Singelis, Theodore M. (1994), "The Measurement of Independent and Interdependent SelfConstruals," Personality and Social Psychology Bulletin, 20 (October), 580-91.

Utz, Sonja (2004), "Self-construal and Cooperation: Is the Interdependent Self More Cooperative than the Independent Self?" Self and Identity, 3 (3), 177-90.

Vaidyanathan, Rajiv, Praveen Aggarwal, and Wojciech Kozlowski (2013), "Interdependent Selfconstrual in Collectivist Cultures: Effects on Compliance in a Cause-related Marketing Context," Journal of Marketing Communication, 19 (1), 44-57.

Velasquez, Alcides and Robert LaRose (2015), "Youth Collective Activism Through Social Media: The Role of Collective Efficacy,” New Media \& Society, 17 (6), 899-918.

Ward, James C. and Amy L. Ostrom (2006), “Complaining to the Masses: The Role of Protest Framing in Customer-Created Complaint Web Sites," Journal of Consumer Research, 33 (2), 220-30.

White, Katherine, Jennifer J. Argo, and Jaideep Sengupta (2012), "Dissociative versus Associative Responses to Social Identity Threat: The Role of Consumer Self-Construal," Journal of Consumer Research, 39 (4), 704-19. 
White, Katherine and John Peloza (2009), "Self-Benefit versus Other-Benefit Marketing Appeals: Their Effectiveness in Generating Charitable Support," Journal of Marketing, $73(4), 109-24$.

White, Katherine and Bonnie Simpson (2013), “When Do (and Don't) Normative Appeals Influence Sustainable Consumer Behaviors?” Journal of Marketing, 77 (March), 78-95.

Winterich, Karen Page and Michael J. Barone (2011), "Warm Glow or Cold, Hard Cash? Social Identity Effects on Consumer Choice for Donation Versus Discount Promotions,” Journal of Marketing Research, 48 (5), 855-68.

Zhang, Haisu and Weizhi Chen (2018), "Backer Motivation in Crowdfunding New Product Ideas: Is It About You or Is It About Me?" Journal of Product Innovation Management, $36(2), 241-62$.

Zhang, Yinlong and Adwait Khare (2009), "The Impact of Accessible Identities on the Evaluation of Global versus Local Products," Journal of Consumer Research, 36 (3), $524-37$.

Zlatev, Julian J. and Dale T. Miller (2016), "Selfishly Benevolent or Benevolently Selfish: When Self-interest Undermines versus Promotes Prosocial Behavior,” Organizational Behavior and Human Decision Processes, 137, 112-22.

Zvilichovsky, David, Shai Danzinger, and Yael Steinhart (2018), "Making the Product Happen: A Driver of Crowdfunding Participation," Journal of Interactive Marketing, 41 (February), 81-93. 